\title{
The bacteriophage efficiency and antibiotics susceptibility against Sudanese local bacteria species Escherichia coli and Staphylococcus aureus
}

\author{
Ayman A. Elshayeb ${ }^{1}$, Atif A. Elagib ${ }^{2}$ and Sanaa O. Yagoub ${ }^{3}$ \\ ${ }^{1}$ Department of Microbiology -Faculty of Science and Technology-Alneelain University- \\ Khartoum-Sudan \\ ${ }^{2}$ Department of Immunology and Biotechnology-Tropical Medicine Research Institute \\ (TMRI)-National Centre for Research (NCR)-Khartoum-Sudan \\ ${ }^{3}$ School of Animal production -Faculty of Agricultural Technology and Fisheries Science - \\ Alneelain University-Khartoum-Sudan
}

\begin{abstract}
This study was held on the in vitro tests for the bacteriophages and their efficiency comparing with the antibiotics susceptibility in destroying bacteria. In broth media the affection of the bacteriophage interactions with bacteria showed increasing of the bacteriophages and decreasing of bacteria due to culture turbidity that showed statistical significant of Escherichia coli and Staphylococcus aureus phages samples' light transmission $\mathrm{P}>0.05$. On solid media the affection of the bacteriophage was recognised by the phage plaque formation on bacterial cultures. The antibiotics susceptibility against the bacteria showed statistical significant $P<0.05$ for $E$. coli and $\mathrm{P}<0.05$ for $S$. aureus. The protein profiles of $E$. coli bacteriophage showed three major bands with molecular weight mass of 47, 35 and 16 kilo Dalton and 34 and $20 \mathrm{kDa}$ for $\mathrm{S}$. aureus phage, the band of $35 \mathrm{kDa}$ was the common shared peak between the phage and the bacterial host due to the bacteriophage lytic cycle. The study showed approximately similar results for the mechanical action of the bacteriophage on the selected bacteria species and the mode of action of antibiotics.
\end{abstract}

Keywords: Antibiotics/ Bacteriophage/ Escherichia coli/ Pathogenic bacteria/ Protein profile/ Stabilisation Station /Staphylococcus aureus/.

\section{INTRODUCTION}

Antimicrobial phage therapy trials have demonstrated phage infection of the increasing incidence resistant bacteria against most or all known antibiotics especially (hospital-acquired) infections, (Kasman, 2005). Phages specific for over 100 bacterial genera have now been isolated (Serwer et al., 2007). All therapeutic phages were virulent, capable of completely lysing the bacteria being treated, (Alavidze et al., 2001). Bacterial levels and phage sensitivity were continually monitored, and the phage(s) being used were changed if the bacteria lost their sensitivity, (Slopek et al., 1984 and 1985). Avoiding the problems engendered by lysogeny and the problems of bacterial resistance this solved by the use of well-chosen mixtures of phages with different receptor specificities against each type of bacterium as well as of phages against the various bacteria likely to be causing the problem in multiple infections. The major categories of infections treated were long-persisting suppurative fistulas, septicemia, abscesses, respiratory tract suppurative infections and bronchopneumonia, purulent peritonitis and furunculosis. Not infrequently, using phage in conjunction with other antibiotics was shown to give better results than either the phage or the antibiotic alone, (Summers, 1999). The phage treatment was more effective than using such antibiotics as tetracycline, streptomycin, ampicillin, trimethoprim and sulfafurazole. The results were particularly effective if the phage were present before or at the time of bacterial presentation, and if multiple phages with different attachment specificities were used. Appropriate oral agents include ampicillin, a cephalosporin, cortimoxazole, nalidixic acid, nitrofurantion, a sulphonamide and tetracycline. Despite extensive intervention strategies, human $E$. coli infections still occur, bacteriophages have been used successfully as antibacterial agents in both human and veterinary medicine and are one potential 
preharvest E. coli control strategy, (Fischetti, 2001). The fact that $E$. coli is also a normal constituent of the gut flora of humans could present a peculiar problem for phage therapy of $E$. coli diarrhea. Therefore, the phage selection should be investigated individually for their lytic potential on nonpathogenic $E$. coli strains (Chennoufi et al., 2004). Staphylococci in general are sensitive to many antibiotics, such as benzyl penicillin, cloxacillin, cephlosporins, tetracycline, chloramphenicol, erythromycin, fucidin, clindamycin, vancomycin, streptomycin and gentamicin, (Breithaupt, 1999). Many of the hospitals' strains are also resistant to several other antiStaphylococcal antibiotics (multi- resistant strains) and these strains are often responsible for hospital cross infection and may be highly virulent. The multiresistant hospital Staphylococci have probably arisen by a succession of mutations conferring resistance to these different drugs in strains that were at first only penicillin resistant, in addition, these MRSA strains also frequently exhibit resistance to a variety of other common antibiotics (Lowy, 2003). The prevalence, in hospital, of strains resistant to a particular antibiotic is related to the amount of that antibiotic used in the hospital and the predominance of multi- resistant strain may be maintained by the widespread use of any one of the antibiotics to which it is resistant, (Deshpande et al., 2004). Since different strains of $S$. aureus differ in sensitivity to different antibiotics, the choice of antibiotic for use in treatment of a patient should be based on the results of sensitivity tests made on a culture of the strain isolated from the patient, (Geisel et al., 2001). S. aureus, a cause of wound and soft-tissue infection, is often resistant to all ß-lactam antibiotics, and strains resistant to vancomycin occur surgical infections may become untreatable. (Wills et al., 2005). The increasing prevalence of antibiotic-resistant Staphylococci has prompted the need for antibacterial controls other than antibiotics, a lytic bacteriophage (phage K) was assessed in vitro for its ability to inhibit emerging drug-resistant $S$. aureus strains from hospitals and other species of Staphylococcus isolated. Phage $\mathrm{K}$ is a polyvalent phage with a broad host range, inhibiting both coagulase-positive and -negative Staphylococci, it is a member of the family Myoviridae, the origin of phage $\mathrm{K}$ is unclear but it is identical to phage Au2 which be derived from the $\mathrm{H}$ strain of $\mathrm{S}$. aureus. In vitro inhibitory assays, phage $\mathrm{K}$ lysed a range of clinically isolated methicillin-resistant $S$. aureus (MRSA) strains, S. aureus with heterogeneous vancomycin resistance, and teicoplanin-resistant strains. The results enforce the principle that, while certain target bacteria may be relatively insensitive to lytic phage, this can be overcome by obtaining modified phage variants from passage of the phage through the insensitive strains, (O'Flaherty et al., 2005).Phage display is a powerful in vitro selection technique to study protein ligand interactions and to isolate target - specific ligands. The peptide or protein is genetically fused to a coat protein on the surface of the phage, while the DNA encoding the fusion products is integrated within the phage genome. This physical linkage between the displayed protein and the DNA encoding allows a fast screening of enormous numbers of different proteins or peptides (phage library). However, for most proteomic applications, the lasting objectives are to functionally display all proteins and to minimize any selection pressure or expression bias. Improvements in display technologies in these areas could potentially provide an essential interface between genomic proteins and physiologically significant biomolecules and therapeutic molecules, (Li, 2000).

\section{MATERIALS AND METHODS}

Bacteria isolation and identification: Escherichia coli and Staphylococcus aureus were isolated from Soba Stabilization Station and subjected to test against bacteriophages isolated from the same location. The identification tests for these bacteria were done according to (Cowan, 1981), (Harrigan and McCance, 1993), (Cheesbrough, 1994) and (Heritage et al., 1996).

\section{Susceptibility of isolated bacteria:}

Toward antibiotics: Isolated bacteria were subcultured into a suitable broth medium, (nutrient broth) and incubated at $37^{\circ} \mathrm{C}$ for $24 \mathrm{hrs} .0 .1 \mathrm{ml}$ of culture was poured on to the surface of previously poured and well-dried agar plate. The culture was spread over the plate and allowed to dry. An antibiotic disc (Axiom multi disc - Axiom Laboratories, New Delhi India) was placed on the plate, in the centre and over the surface of the agar; a flamed forceps with aseptic precautions was used. The plate was incubated at $37^{\circ} \mathrm{C}$ for $24 \mathrm{hrs}$ and the presence of zones of inhibition around the tips of the disc were recorded.

Toward bacteriophages: The susceptibility of bacteria toward bacteriophages was determining by plaque-forming units per $\mathrm{ml}(\mathrm{PFU} / \mathrm{ml})$ on bacterial cultures. To obtain this value, a series of dilutions (the tubes with $9.0 \mathrm{ml}$ distilled water were labelled $10^{-}$ $5,10^{-6}, 10^{-7}$, and $10^{-8}$ ). One of the virus stocks was Chosen and dispended in the serial dilution the virus 
sample was mixed with a dense bacterial culture and melted with soft agar and then spread over the surface of a base agar plate and used to infect bacteria. The plaques produced were then counted according to the number adjusted for the dilution to investigate bacteriophage specificity toward the specific bacteria.

\section{Protein profiles:}

Preparation of the bacteria antigens: According to (Ding, 2001), Bacteria were incubated at $30^{\circ} \mathrm{C}$ in nutrient broth with SM buffer (for 1 litre: $\mathrm{NaCl} 5.8 \mathrm{~g}$, $\mathrm{MgSO}_{4} .7 \mathrm{H}_{2} \mathrm{O} 2.0 \mathrm{~g}, 2 \%$ gelatine solution , Tris $\mathrm{HCl} 1 \mathrm{M}$ (pH 7.5) $50 \mathrm{ml}$. Distil water), for $2-3$ days, then cells were removed from media by centrifugation for 3 minutes at $15,000 \mathrm{rpm}$. The supernatants were discards and the precipitations were filtered by Millipore filter with a pore size of $0.45 \mu \mathrm{m}$ and stored at $-50^{\circ} \mathrm{C}$. afterward, the samples were crushed by glass rod and homogenised in sterile distilled water in volume 15 times less than their initial volume.

Preparation of the bacteriophage antigens: $E$. coli and $S$. aureus bacteriophages were prepared by inoculating the bacteria in semi solid medium Tryptone Soy Agar- (TSA), after 4 hours of incubation at $4^{\circ} \mathrm{C}$, the phage - containing solution was filtered by filter paper with a pore size of $0.45 \mu \mathrm{m}$. Chloroform $(3 \%$ $\mathrm{v} / \mathrm{v}$ ) was used to lyse the bacterial cells, and cellular debris were subsequently removed by centrifugation for 5 minutes at $5000 \mathrm{rpm}$. The bacteriophage protein were then pelted by centrifugation for 30 minutes at $5000 \mathrm{rpm}$. The supernatant was discarded and the pellets were resuspended in $150 \mu \mathrm{l}$ fresh SM buffer and stored at $4^{\circ} \mathrm{C}$, afterward, the samples were freeze dried and homogenised in sterile distilled water in volume 15 times less than their initial volume.

Sodium dodocyl sulphate polyacrylamid gel electrophoresis (SDS-PAGE): This was done according to (Laemmli, 1970)

Computational analysis: The Microsoft Excel program was used for the statistical analysis, and the bioinformatics programmes UN - SCAN - IT version 5 and Image $136 \mathrm{~b}$ were used for the protein molecular mass weight analysis.

\section{RESULTS}

\section{Susceptibility of isolates towards antibiotics:}

Escherichia coli : E. coli showed sensitivity towards: Ciprofloxacin, Pefloxacin, Ofloxacine, Tetracycline, Amikacin, Gentamicin, Piperacillin and Ceftizoxime, the largest inhibition zone was shown with Ciprofloxacin as $29 \mathrm{~mm}$ diameter. E. coli was resistant to Chloramphenicol, Cefotaxime, CoTrimoxazole and Ampicillin / Sulbactam as shown in figure (1).

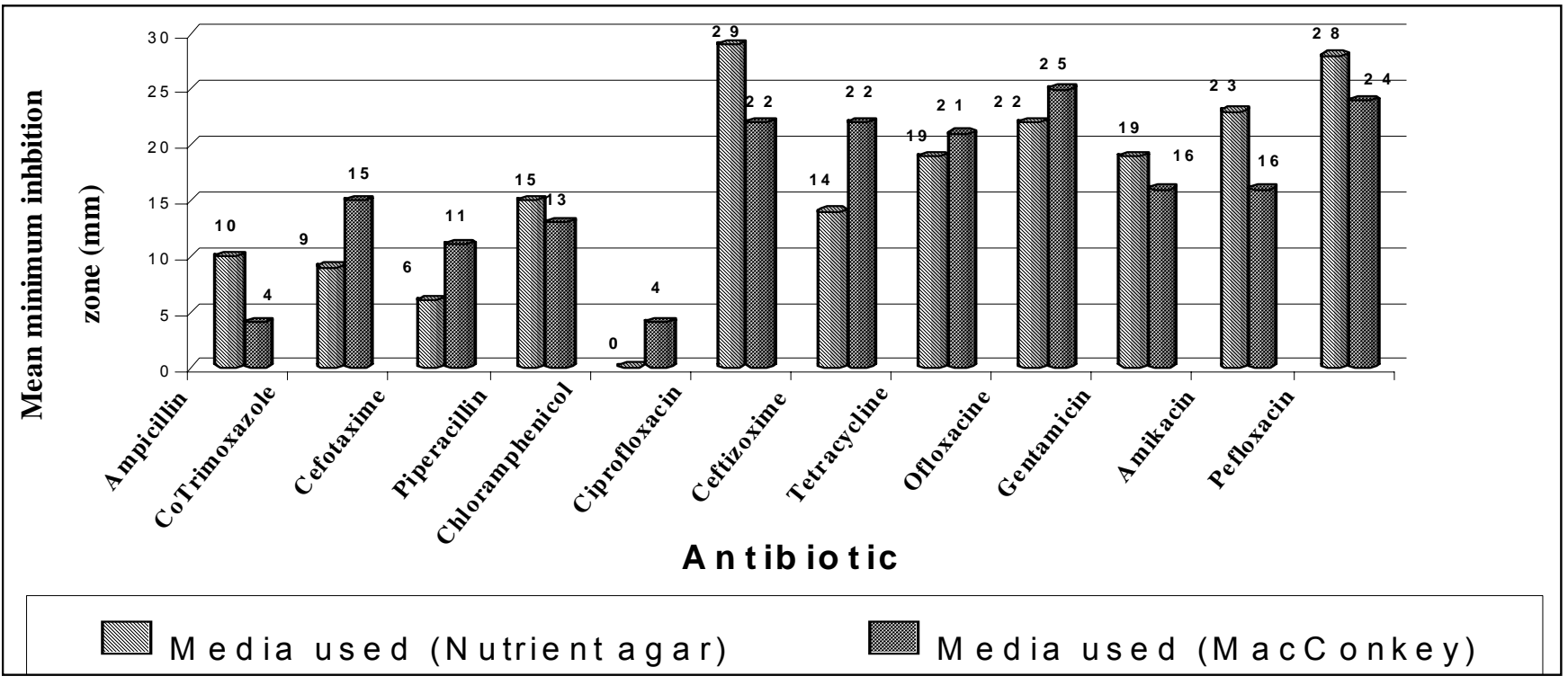

Fig 1. Average of E. coli susceptibility toward antibiotics 
Staphylococcus aureus: he S. aureus was sensitive to Lincomycin, Cloxacillin, Ciprofloxacin, Tetracycline, Ofloxacine, Ampicillin / Sulbactam and Cephalexin and the largest inhibition zone was shown with
Lincomycin as $42 \mathrm{~mm}$ diameter. S. aureus showed resistant towards: Roxythromycin, Gentamicin, Pefloxacin, Cefotaxime, and Co - Trimoxazole, as shown in figures (2).

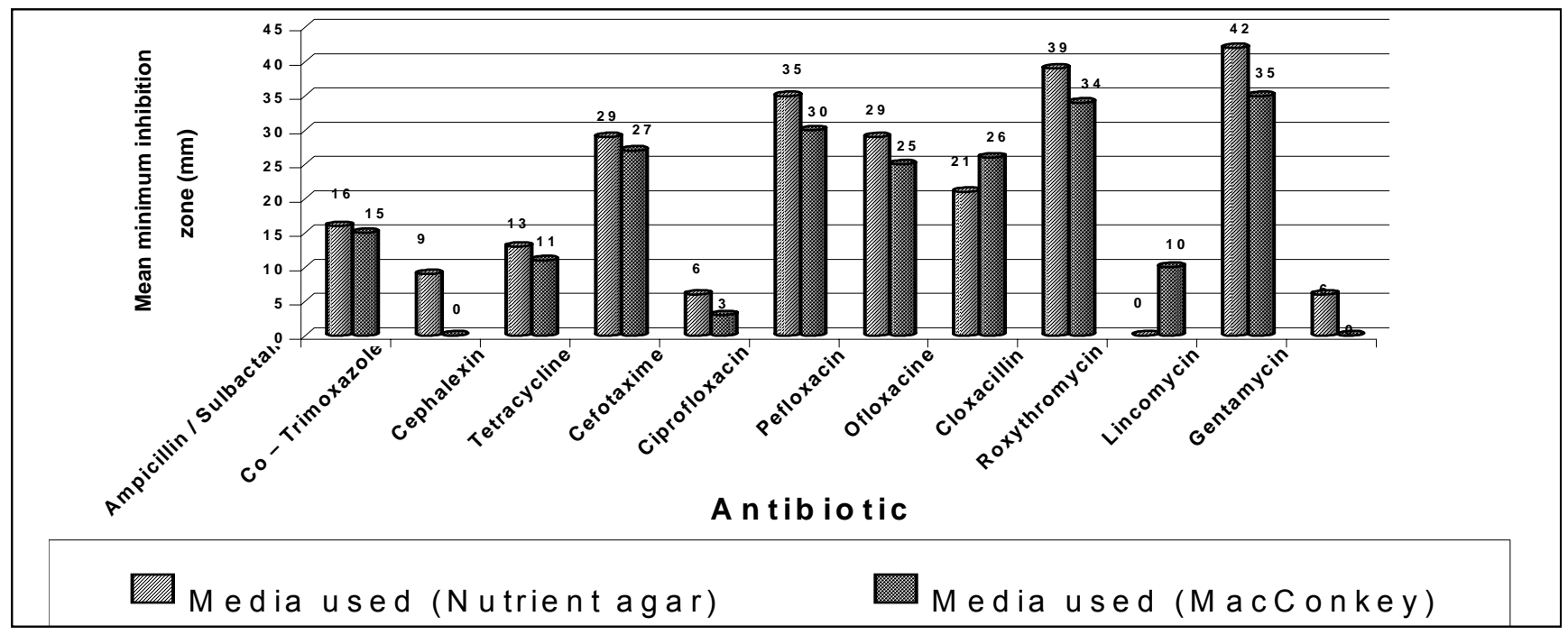

Fig 2. Average of $S$. aureus susceptibility toward antibiotics

Comparative Statistical analysis: In broth media the affection of the bacteriophage interactions with their bacteria were recognised by the spectrophotometer, where the readings of the turbidity for the first and second infection showed statistical significant of $E$. coli samples' transmission from the anaerobic and facultative ponds $P>0.05$, facultative and maturation $\mathrm{P}<0.05$ and anaerobic and maturation $P>0.05$ respectively. Whilst, the $S$. aureus samples' transmission from the anaerobic and facultative $\mathrm{P}<0.05$, facultative and maturation $\mathrm{P}<0.05$ and anaerobic and maturation $\mathrm{P}>0.05$ respectively. On solid media the affection of the bacteriophage was recognised by the phage plaque formation on bacterial cultures, where the Miles and Misra drop technique gives uncountable plaques on selective media Eosin Methylene Blue for the E.coli bacteriophage and Mannitol Salt Agar for the $S$. aureus bacteriophages from the titrations $10^{-6}$ and $10^{-7}$ dilutions. The antibiotics susceptibility against the bacteria showed statistical significant $\mathrm{P}<0.05$ for E.coli and $\mathrm{P}<0.05$ for S. aureus samples. Figure (3)

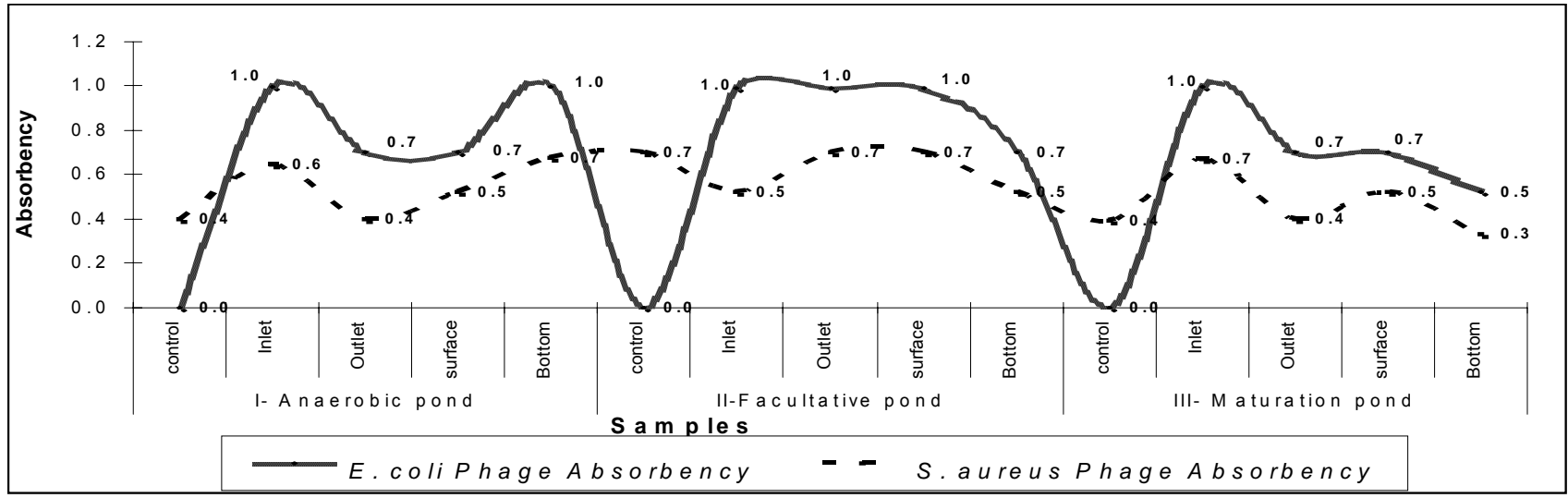

Fig 3. Samples absorbencing Beer Lambert equation 
E. coli showed more sensitivity towards the extracted phage than $S$. aureus on solid media, the $E$. coli phages showed more plaques and clearness than $S$. aureus phages. While in liquid media the activity of the phage was more effective against $S$. aureus than $E$. coli, where S. aureus liquid culture showed more clearness than $E$. coli culture when inoculated with phage after 48 hours according to their culture density for light absorption, Table (1).

Table 1: Phage activity against corresponding bacteria in liquid media and on solid media.

\begin{tabular}{|l|l|l|l|l|}
\hline \multirow{2}{*}{ Bacteria } & \multicolumn{2}{|c|}{ Liquid media } & & \multicolumn{2}{c|}{ Solid media } \\
\cline { 2 - 5 } & Turbidity & Absorbency & Numbers of plaques & Large \\
\hline E. coli & High turbidity & 0.71 & Many plaques & Small \\
\hline S. aureus & Low turbidity & 0.55 & Less plaques & \\
\hline
\end{tabular}

Comparison between phage and bacteria protein profiles: The protein profiles of $E$. coli bacteriophage showed three bands for samples collected from E.M.B Agar as shown in figure (4) and the $S$. aureus bacteriophages showed only two bands in Nutrient broth.Comparing with the molecular weight marker, the mobilised proteins of the $E$. coli phage were 46,35 and $24 \mathrm{kDa}$, meanwhile the $S$. aureus phage were 34 and $20 \mathrm{KDa}$, the molecular weight mass of the gel results analysis by the bioinformatics programmes showed molecular masses of 47,35 and $16 \mathrm{kDa}$ for the $E$. coli phage, figure; (5),. The protein profile of $E$. coli bacteria showed clear nine bands with molecular weight ranged between 96 and $14 \mathrm{KDa}$ figure (5). The obtained bands of the $E$. coli phage and the $E$. coli bacteria were compared, one band of $35 \mathrm{KDa}$ showed typical similarity in both $\mathrm{E}$. coli phage and $\mathrm{E}$. coli bacteria as shown in figure (5)

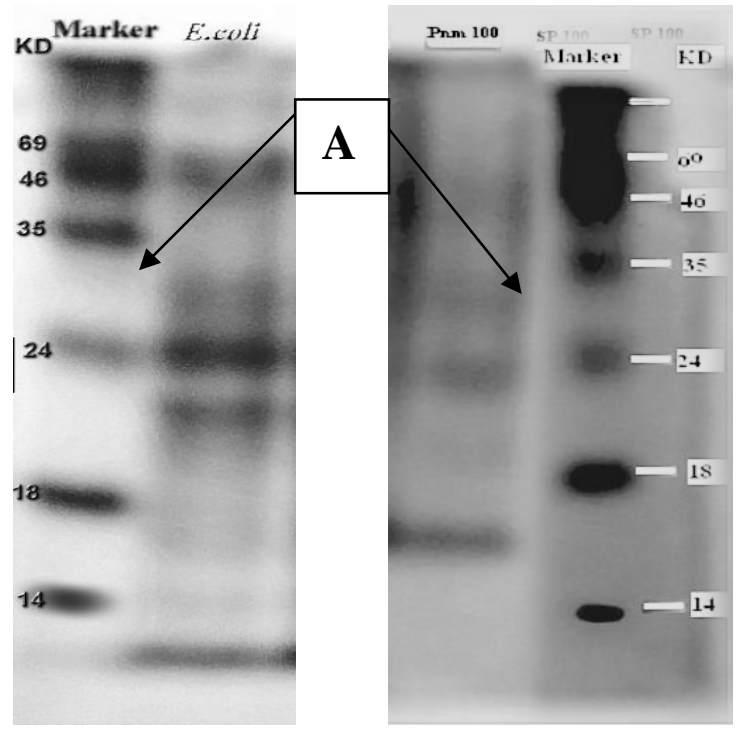

E. coli Bacteria

E. coli Phage

Figure (4): E. coli bacteria \& Phage protein profile

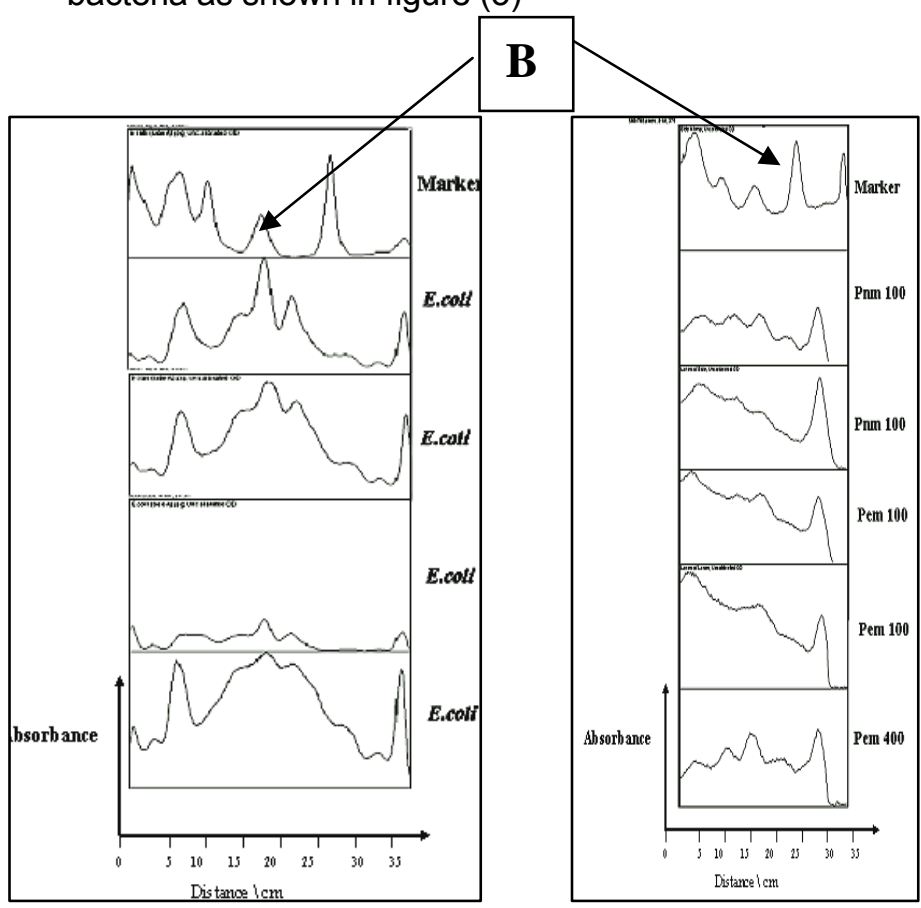

Fig 5: E. coli bacteria \& Phage protein profile analysis

A: Band of $35 \mathrm{kD}$. B: Common shared peak of band $35 \mathrm{kD}$. 


\section{DISCUSSION}

In this study it was clear that the isolated bacteria (Escherichia coli and Staphylococcus aureus) were resistant to common antibiotics, the multi resistance of these two important bacteria was well known due to hazardous factors supported by the fact that they are commonly wide-spreaded in the environment as stated by (Stewart, 2003 and Johnson et al.,2005). The resistance of $S$. aureus toward multi-antibiotics was reported by (Breithaupt, 1999, Zimmer, et al.,2002 and Deshpande et al., 2004). While E. coli susceptibility was reported by (Casswall et al., 2000). The modes of action of antibiotics towards E. coli showed the bacteria were sensitive towards; Pefloxacin, Ciprofloxacin, Ofloxacine, Tetracycline, Amikacin, Gentamicin, Piperacillin Ceftizoxime, and Co Trimoxazole, and were resistant to Chloramphenicol, Cefotaxime and Ampicillin / Sulbactam this agreed with (Li et al., 2007) who stated that antimicrobial susceptibility profiles for $E$. coli isolates displayed resistance to trimethoprim-sulfamethoxazole $(100 \%)$, oxytetracycline $(100 \%)$, ampicillin (83\%), enrofloxacin $(83 \%)$, and ciprofloxacin (81\%), respectively. Among the phenicols, resistance was approximately $79 \%$ and $29 \%$ for chloramphenicol and florfenicol. S. aureus bacteria showed sensitivity towards: Roxythromycin, Gentamicin, Ciprofloxacin, Tetracycline, Pefloxacin, Cefotaxime, Ofloxacine, Ampicillin / Sulbactam and Cephalexin,. The S. aureus was resistant to Cloxacillin, Lincomycin and Co - Trimoxazole, this agreed with (O'Flaherty et al., 2005) who reported that the rapid emergence of penicillin-resistant $S$. aureus led to the use of methicillin and related drugs for treatment of infections, methicillin-resistant $S$. aureus (MRSA) strains emerged and have exhibit resistance to a variety of other common first-line antibiotics, ampicillin and penicillin and $36.8 \%$ of $S$. aureus isolates ribotyped belonged to multidrug-resistant, oxacillin-resistant $S$. aureus strains.

The efficiency of isolated phage against $E$. coli and $S$. aureus showed remarkable inhibition of growth of the bacteria at both solid and liquid media this might be due to physio-chemical changes and difference in motility of these two bacteria. The mechanical action of bacteriophage on selected bacterial species depend on their receptors that adsorb them to their hosts, the relation between the bacteria and their corresponding phages was shown in the present study and these confirm the findings of (Schirmer, 1998 and Wang et al., 2000) who reported that some proteins of the bacterial outer membrane acts as the receptors for their phages. Another means of controlling phages is through the use of strain rotation based on phage species sensitivity and specificity on $E$. coli and $S$. aureus this agreed with (Moineau, 1999) who explained that the biology of host-phage interactions showed the mechanisms by which some phages may differ from others in infecting bacteria species, growth characteristics of $E$. coli phages indicate that they are adapted to live with their $E$. coli hosts in the intestinal tract, so $E$. coli phages have traditionally been isolated from sewage, where they arrived, presumably, after passing through the Gastro interites tracts of animals inhabited by coliform bacteria, also $S$. aureus showed susceptibility towards phages this was observed as confluent lysis or individual plaques in the bacterial lawn after overnight incubation this agreed with (Kasman, 2005) who found that isolates from different compartments of the same location had identical phage susceptibility profiles that were considered to be the same bacteria strain. The bacteriophage plaque formation is the most useful tool for studying the bacteria susceptibility towards phage, studying the phage morohology on solid agars and isolating pure phage stock. For the presence of lytic phage using standard microbiological methods such as plaque assay activity test, this agreed with (Kasman, 2005) who added that a positive result in the phage assay leads to a substitution of the existing bacterial culture for another phage inoculation to detected by plaque assay which can usually be reactivated to the free state by treatment of the bacteria with phage and produced different culture conditions for the enrichment of phage recovery, cultures under these conditions were assayed for the presence of phage by spotting on semi solid agar overlays.

The bacteriophages and bacteria proteins were detected in this study by the Sodium Dodecyl Poly Acrylamide Gel Electrophoresis (SDS-PAGE). The protein profiles of the $E$. coli bacteria showed nine major bands more than it's phage, these result indicated that bacterial DNA encoded proteins more than their corresponding phage due to the fact that bacterial cell is more complicated organism than viruses and that bacteria differ in their genetically composition, cell structure, function and size appearance from viruses which are more simplest in their structure and size and have no ability to produce energy or live independently, these also reported by (Mueller 2000 and Ucan et al., 2005). The similarity of phage protein bands to those presence in their corresponding bacteria confirmed the scientific fact that viruses depend on their host completely to supply tem by their requirement from all macromolecules 
other than genome during their multiplication. The molecular weight of bands obtained with $E$. coli phage was similar for phage HK97 of E. coli that isolated and identified by (Conway et al., 1995 and Juhala, et al., 2000). Meanwhile, the $S$. aureus phage protein profile showed two major bands with molecular weight similar to the same bacterial phage reported by both (Kaneko et al.,1997 and Narita et al., 2001), on the other hand (Wills et al., 2005) isolated and identified other protein bands with different molecular weight that were not detected in our study, these might be due to that $S$. aureus have different serotypes that differ in their genetical and antigenical structure and the failure to detect the bands that recognized by (Wills et al., 2005), might be due to use of different serotype of $S$. aureus and these also explain the difference in molecular weights and number of bands of both phages.

\section{CONCLUSION}

The study showed approximately similar results for the mechanical action of the bacteriophage on the selected bacteria species and the mode of action of antibiotics. The study recommended that it is preferably to manipulate bacterial infections by the Bacteriophage therapy in case of the antibiotic resistant bacteria.

\section{REFERENCES}

Alavidze. Z, A. Sulakvelidze, and M.J. Glenn, (2001). Bacteriophage Therapy. Antimicrobial Agents and Chemotherapy.45 : 649-659.

Breithaupt, H., (1999). The new antibiotics. Nat. Biotechnol. 17:1165-1169.

Casswall, T.H., Sarker S.A., Faruque S.M., Weintraub A., Albert M.J., Fuchs G.J., Alam N.H., Dahlstrom A.K., Link H., Brüssow H., and Hammarström L., (2000). Treatment of enterotoxigenic and enteropathogenic Escherichia coli-induced diarrhoea in children with bovine immunoglobulin milk concentrate from hyperimmunized cows: a double-blind, placebocontrolled, clinical trial. Scand. J. Gastroenterol. 35:711.

Cheesbrough, M., (1994). Medical laboratory manual for tropical countries. Vol II microbiology. University press, Cambridge England.

Chennoufi S.C., J. Sidoti, A. Bruttin, E. Kutter, S. Sarker, and $\mathrm{H}$. Brüssow, (2004). In Vitro and In Vivo Bacteriolytic Activities of Escherichia coli Phages: Implications for Phage Therapy. Antimicrobial Agents and Chemotherapy.48: 2558-2569.
Conway, J.F., R. L. Duda, N. Cheng, R. W. Hendrix, and A. C. Steven, (1995). Proteolytic and conformational control of virus capsid maturation: the bacteriophage HK97 system. J. Mol. Biol. 253:86-99.

Cowan, S.T. (1981). Cowan and Steel's Manual for the identification of Medical Bacteria. 4th edn. Cambridge University Press, Cambridge.England.

Deshpande, L.M., T.R. Fritsche, and R.N. Jones, (2004). Molecular epidemiology of selected multidrug-resistant bacteria: a global report from the SENTRY antimicrobial surveillance program. Diagn. Microbiol. Infect. 49:231-236.

Ding, H., (2001). Functional characterization of Pura in vivo and in vitro - Pura knock-out mice and Pura DNA unwinding activity. PhD Thesis. Ludwig - Maximilians University Munich, Germany.

Fischetti, V.A., (2001). Phage antibacterials make a comeback. Nat. Biotechnol. 19:734-735

Geisel R, F.J. Schmitz, A.C. Fluit, and H. Labischinski,(2001). Emergence, mechanism, and clinical implications of reduced glycopeptide susceptibility in Staphylococcus aureus. Eur J Clin Microbiol Infect. 20: 685-97.

Harrigan W.F. and M.E. McCance, (1993). Laboratory methods in food dairy microbiology. Academic Press. Harcourt Brace and Company Publishers. London U.K.

Heritage, J., Evans E.G., and R.A.,Killington, (1996). Introductory to Microbiology, $1^{\text {st }}$ Edn, University press Cambridge England.

Johnson, J.R., Murray, A.C., Kuskowski, M.A., Schubert, S., Prere, M.F., and Picard B., (2005). Distribution and characteristics of Escherichia coli clonal group A. Emerg Infect Dis 11: 141-145.

Juhala, R.J., M.E. Ford, R.L Duda., A Youlton, and R.W. Hendrix, (2000). Genomic sequences of bacteriophages HK97 and HK022: pervasive genetic mosaicism in the lambdoid bacteriophages. J. Mol. Biol. 299:27-51.

Kaneko, J., Kimura T., Kawakami Y., Tomita T., and Kamio Y., (1997). Panton-valentine leukocidin genes in a phage-like particle isolated from mitomycin C-treated Staphylococcus aureus V8 (ATCC 49775). Biosci. Biotechnol. Biochem. 61:1960-1962.

Kasman ,L.M., (2005).Barriers to coliphage infection of commensal intestinal flora of laboratory mice. Virology Journal. 5:3610-3616.

Laemmli, U.K., (1970). Cleavage of structural proteins during the assembly of the head of bacteriophage T4. Nature. 227: 680-685.

$\mathrm{Li}, \mathrm{M} .,(2000)$. Applications of display technology in protein analysis. Nat Biotechnol 18:1251-6. 
Li, X.S, G.Q Wang, X..D. Du., B.A. Cui, S.M Zhang and J.Z Shen, (2007), Antimicrobial susceptibility and molecular detection of chloramphenicol and florfenicol resistance among Escherichia coli isolates from diseased chickens. J. Vet. Sci. 8(3), 243-247

Lowy, F.D., (2003). Antimicrobial resistance: the example of Staphylococcus aureus. J. Clin. Investig. 111:12651273.

Moineau, S., (1999). Applications of phage resistance in lactic acid bacteria. Antonie Leeuwenhoek. 76:377382.

Mueller, M., (2000). Persistent bacterial infections: Identification of immunogenic structure of Borrelia burgdorferi sensu lato and Chlamydophila pnemoniae by phage surface display. PhD Thesis. Konstanz Univeristy Germany.

Narita, S., Kaneko J., Chiba J., Piemont, Jarraud Y., J. Etienne S., and Kamio Y., (2001). Phage conversion of Panton-Valentine leukocidin in Staphylococcus aureus: molecular analysis of a PVL-converting phage, phiSLT. Gene 268:195-206.

O'Flaherty S., R.P. Ross, W. Meaney, G.F. Fitzgerald, M.F. Elbreki, and A. Coffey, (2005). Potential of the polyvalent Anti-Staphylococcus bacteriophage $\mathrm{K}$ for control of antibiotic-resistant Staphylococci from hospitals. Applied and Environmental Microbiology. 4:1836-1842.

Schirmer, T., (1998). General and specific porins from bacterial outer membranes. J. Struct. Biol. 121: 101109.

Serwer P., S.J. Hayes, J.A. Thomas and S.C. Hardies, (2007). Propagating the missing bacteriophages: a large bacteriophage in a new class. Virology Journal. 4(21)10.11
Slopek, S., A. Krukowska; B. Dabrowska and M. Dabrowski, (1985). Results of bacteriophage treatment of suppurative bacterial infections. IV. Evaluation of the results obtained in 370 cases. Arch Immunol Ther Exp. 33(2):219-40

Slopek, S., I. Durlakova B. , Dabrowska, M. Dabrowski and A. Krukowska, (1984). Results of bacteriophage treatment of suppurative bacterial infections III. Detailed evaluation of the results obtained in further 150 cases. Arch. Immunol. Ther. Exp. 32:317-335.

Stewart, C.M., (2003). Staphylococcus aureus and Staphylococcal enterotoxins. In foodborne microorganisms of public health significance. $6^{\text {th }}$ ed, AIFST (NSW) Branch, Sydney, pp359-380.

Summers, W.C., (1999). How bacteriophage came to be used by the Phage Group. J. Hist. Biol. 26:255-267.

Ucan, U.S., Acik L., Celebl A., Erganis O. and Arslan E., (2005). Plasmids and proteins patterns of Escherichia coli isolated from bovine mastitis in Konya, Turkey. Turk Vet Anim Sci. 29: 475 - 480.

Wang, J., Hofnung, M., and Charbit A., (2000). The Cterminal portion of the tail fiber protein of bacteriophage lambda is responsible for binding to LamB, its receptor at the surface of Escherichia coli K12, J. Bacteriol. 182: 508-512.

Wills Q.F., C. Kerrigan, and J.S. Soothill, (2005). Experimental Bacteriophage Protection against Staphylococcus aureus Abscesses in a Rabbit Model. Antimicrobial Agents and Chemotherapy. 49: 312201221.

Zimmer M., Scherer S., and Loessner M. J., (2002). Genomic Analysis of Clostridium perfringens Bacteriophage $Ф 3626$, Which Integrates into guaA and Possibly Affects Sporulation. Journal of Bacteriology. 184(16): 4359-4368. 